\title{
Screening of sunflower (Helianthus annus L.) accessions under drought stress conditions, an experimental assay
}

\author{
Humera Razzaq ${ }^{1}$, M. Hammad Nadeem Tahir ${ }^{1}$, Hafeez Ahmad Sadaqat ${ }^{1}$ and Bushra Sadia ${ }^{2}$
}

${ }^{1}$ Plant Breeding and Genetics, University of Agriculture, Faisalabad-38040, Pakistan. ${ }^{2}$ Centre of Agricultural Biochemistry and Biotechnology, University of Agriculture, Faisalabad-38040, Pakistan. Corresponding

author:humerarazzaq@gmail.com

\begin{abstract}
Drought is the major abiotic stress that limits the crop production at drastic level. Screening of tolerant accessions from available germplasm is the basic step in plant breeding. Sunflower is becoming popular and major oilseed crop in world but unfortunately it is drought sensitive. Screening in field has uncertainties due to the uncontrolled conditions, interaction of biotic and abiotic stresses and variability in environmental factors. Response of the sixty sunflower accessions to drought stress at germination and seedling stage was examined by using polyethylene glycol (PEG-6000) as drought simulator under laboratory. Normal and drought stress treatments i.e. $\mathrm{T}_{1}=$ zero (control), $\mathrm{T}_{2}=-1.33 \mathrm{MPa}$ and $\mathrm{T}_{3}=-1.62 \mathrm{MPa}$ were developed by dissolving 0,15 g and $20 \mathrm{~g}$ Polyethylene Glycol (PEG-6000) in $100 \mathrm{~mL}$ distilled water and a completely randomized design with three replications were used. Promptness, germination, seedling height, fresh weight, dry weight and stress indexes were determined to evaluate the response of sunflower accessions under normal and PEG simulated drought stress treatments. Principal component analysis was used to select the drought tolerant and sensitive accessions. The accessions 017583, A-75, A-79, 017592, G-33, A-48, A-23, G-61, HBRS-1 and 017566 were selected as drought tolerant while, CM-621, 017577, HA-124, HA-133, HA-342 and HA-341 were as drought sensitive. This study may be helpful for the comparison of drought indexes in a controlled experimental assay and for the identification of drought tolerant sunflower cultivars to be used in further breeding programs.
\end{abstract}

Keywords: Drought stress, polyethylene glycol (PEG-6000), principal component analysis, seedling traits, sunflower accessions 


\section{Introduction}

Food security will be a great challenge for the world at least another 40 years due to the continuous increase in the population and high consumption growth rate (Ma et al., 2016). Unavailability of the adequate water supply is a very crucial factor affecting the plant growth and development. Ultimately it seriously decreases food production. Drought is one of the major abiotic stress which causes low yield especially in arid and semi-arid regions of the world (Viscardi et al., 2016; Tian et al., 2016). Due to the climate change, severe droughts are expected in future. Sunflower being an oilseed crop, is becoming popular cultivar and it contributes globally about $87 \%$ in vegetable oil production (Murphy, 2010; Razzaq et al., 2015). But unfortunately, unequal distribution of the rainfall and water shortage during its growing season has severe reduction in achene and in oil yield (Tahir et al., 2002). Sunflower is very sensitive to water scarcity at various stages. There are certain stages at which plants are badly affected by the drought such as germination, seedling and flowering (Ashraf and Mehmood, 1990). Seed germination is however, the most critical and sensitive stage so, when this stage faces drought, seeds must compromise for the establishment of the seedlings (Albuquerque and de Carvalho, 2003).

Germination percentage decreases and the timing process also increases at higher drought levels (Smok et al., 1993; Sajjan et al., 1999). It has adverse effects at germination and seedling stage in sunflower as reported by Mohammad et al. (2002) as well as in wheat (Dhanda et al., 2004) and sugar beet (Sadeghian and Yavari, 2004). Although various genotypes of sunflower had different responses to all treatment of stresses, germination of sunflower was inhibited at an osmotic pressure lower than -5 bars in the presence of polyethylene glycol (PEG-6000) Smok et al. (1993) and Ma et al. (2016). Therefore, need of the time is to grow drought tolerant cultivars of sunflower which can express their full yield potential even under severe water scarcity, are needed. These drought tolerant cultivars will contribute to more stable sunflower production.

Selection of drought tolerance accessions from the available germplasm is the basic step to develop drought tolerant varieties or hybrids. Plant breeders have used various selection methods to screen for drought tolerant accessions and traits that will contribute to drought tolerance. However, uncontrolled conditions, heterogeneity in soil, huge amount of plant material, time and labor experiments in the field, makes the screening experiments more difficult. Hence laboratory experiments are more reliable and easy to conduct as compared to field trials. Under laboratory Polyethylene glycol (PEG-6000) is usually used as drought simulator as it is considered as non-penetrable, harmless and best way to create osmotic stress consequences of drought stress condition (Hu and Jones, 2004; Kaya et al., 2006; Cavallaro et al., 2016).

Drought indexes are quantitative measured that characterize drought levels by assimilating data from one or several variables into a single numerical value. The nature of drought indexes reflects different events and conditions such as soil moisture loss or lowered reservoir levels (Ahmad et al., 2009; Cavallaro et al., 2016). Using this simple method, drought indexes help to communicate all drought levels. These are considered very helpful to study the drought study more efficiently and precisely.

Thus, the main objective of this study was to screen out the drought tolerant and sensitive accessions among sixty germplasm of sunflower (Helianthus annuиs L.) at germination and seedling stage. Stress 
indexes were also compared to select the main drought indexes.

\section{Materials and Methods}

\subsection{Experimental details and treatments}

Experiment was performed in the Sunflower Research Laboratory, Department of Plant Breeding and Genetics, University of Agriculture, Faisalabad. Sixty sunflower (Helianthus annuus L.) accessions (Table 1) were collected from national and international organizations. These accessions were evaluated against drought stress at germination and seedling stage under laboratory conditions. The experiment was laid out in a triplicate completely randomized design with factorial structured treatments.

Table 1. List of sunflower accessions and check hybrids used in experiments

\begin{tabular}{|l|lll|ll|l|}
\hline $\begin{array}{l}\text { University of } \\
\text { Agriculture, } \\
\text { Faisalabad }\end{array}$ & $\begin{array}{l}\text { National Agriculture } \\
\text { Research Centre }\end{array}$ & $\begin{array}{l}\text { United States Department of } \\
\text { Agriculture }\end{array}$ & $\begin{array}{l}\text { Ayub Agricultural } \\
\text { Research Institute }\end{array}$ \\
\hline HBRS-1 & 017564 & 017574 & 017584 & Omskij skorospelyj & HA-U & FH-331 \\
\hline A-79 & 017565 & 017575 & 017585 & Odesskij 19 & RHA-389 & FH-569 \\
\hline A-48 & 017566 & 017576 & 017586 & HA-341 & ANN- & FH-570 \\
& & & & & 2101 & \\
\hline A-75 & 017567 & 017577 & 017587 & HA 342 & HA-124 & FH-580 \\
\hline G-61 & 017568 & 017578 & 017588 & PEMS-R-88 & RHA-418 & \\
\hline G-33 & 017569 & 017579 & 017589 & R-sin-82 & HA-112 & \\
\hline G-56 & 017570 & 017580 & 017590 & R-C-HT-82 & HA-124 & \\
\hline G-8 & 017571 & 017581 & 017591 & F-Yu-82 & HA-133 & \\
\hline G-64 & 017572 & 017582 & 017592 & CM-612 & HA-236 & \\
\hline A-23 & 017573 & 017583 & 017593 & CM-621 & JB-3158 & \\
\hline
\end{tabular}

Three drought treatments i.e. $\mathrm{T}_{1}=$ zero (control), $\mathrm{T}_{2}=-1.33, \mathrm{~T}_{3}=-1.62 \mathrm{MPa}$ were developed by dissolving 0, 15, $20 \mathrm{~g}$ of PEG-6000 (Anala R) per $100 \mathrm{~mL}$ distilled water, respectively Ahmad et al. (2009) and Tsago et al. (2014). Seeds were surface sterilized with $10 \%$ sodium hypochlorite solution for five minutes and then washed five times with distilled water. Five seeds of each accession per replication were planted in separate sterile petri plates of plastic material containing filter papers. Size of the petri plates was $60 \mathrm{~mm} \times 15 \mathrm{~mm}$. Ten $\mathrm{mL}$ of designated treatment solution was applied daily to each petri plate after washing out the previous solution.

Number of seeds germinated was counted daily and data were recorded for 14 days after sowing. Fresh and dry weights and heights of the seedlings were recorded after 14 days of sowing. Seedling dry weights 
were recorded after the drying at $70{ }^{\circ} \mathrm{C}$ in an oven (Isotemp oven 655F). The recorded data were used to compute promptness index (PI), germination stress tolerance index (GSI), seedling height stress tolerance index (SHSI), fresh weight stress tolerance index (FWSI) and dry matter stress tolerance index (DMSI) by using the following formulae Ashraf et al. (2006) and Ahmad et al. (2009).

PI $(\%)=\left\{\mathrm{nd}_{2}(1.00)+\mathrm{nd}_{4}(0.75)+\mathrm{nd}_{6}(0.5)+\mathrm{nd}_{8}\right.$ $(0.25)\} \times 100$

Where $\mathrm{n}$ is the number of seeds germinated at day $\mathrm{d}$

GSI $(\%)=($ PI of stressed seeds $/$ PI control seeds $) \times 100$

SHSI $(\%)=($ Seedling height of stressed plant $/$ Seedling height of control plant) $\times 100$

FWSI $(\%)=($ Fresh weight of stressed plant $/$ Fresh weight of control plant) $\times 100$

DMSI $(\%)=($ Dry matter of stressed plant $/$ Dry matter of control plant) $\times 100$
Statistical Analysis: The recorded data was subjected to analysis of variance following by Steel $e t$ al. (1997) and principal component analysis (PCA) Ghaffari et al. (2012).

\section{Results}

Results related to genetic variability are presented in Table 2. Accessions had significant differences for all the stress indexes except promptness index, while all stress indexes of $\mathrm{T} 2$ and $\mathrm{T} 3$ were significantly different except promptness index, fresh weight and dry matter stress index. Interaction of accessions and treatments was non-significant for all the indexes. This suggests the genetic differences among the accessions under treatments which can be exploited in next breeding program. All the stress indexes T3 showed decrease in as compared to that of T2 except germination stress index (Figure 1).

Table 2. Mean square values from analysis of variance for stress indexes in sunflower accessions under PEG-6000 simulated drought stress conditions

\begin{tabular}{|l|l|l|l|l|l|}
\hline $\begin{array}{l}\text { Source of } \\
\text { variation }\end{array}$ & PI & GSI & FWSI & DMSI & SHSI \\
\hline Replications & 412186 & 25910 & 1140241 & 3.441 & 7671.5 \\
\hline Accessions (A) & 32572 & $3584^{*}$ & $1647976^{*}$ & $2.625^{*}$ & $1491.8^{*}$ \\
\hline $\begin{array}{l}\text { Treatments } \\
(\mathbf{T})\end{array}$ & 217162 & $217162^{*}$ & 176 & 4114049 & $24118.7^{*}$ \\
\hline $\mathbf{A} \times \mathbf{T}$ & 17443 & 1038 & 751461 & 1142907 & 685.8 \\
\hline Error & 89549 & 774 & 607528 & 9539203 & 584.4 \\
\hline
\end{tabular}

$*=$ Significant at 0.05 probability level $\quad * *=$ Significant at 0.01 probability level

$\mathbf{P I}=$ Promptness index, GSI $=$ Germination stress index, $\mathbf{F S W I}=$ Fresh shoot weight index, $\mathbf{D M S I}=$ Dry matter stress index

SHSI $=$ Seedling height stress index 


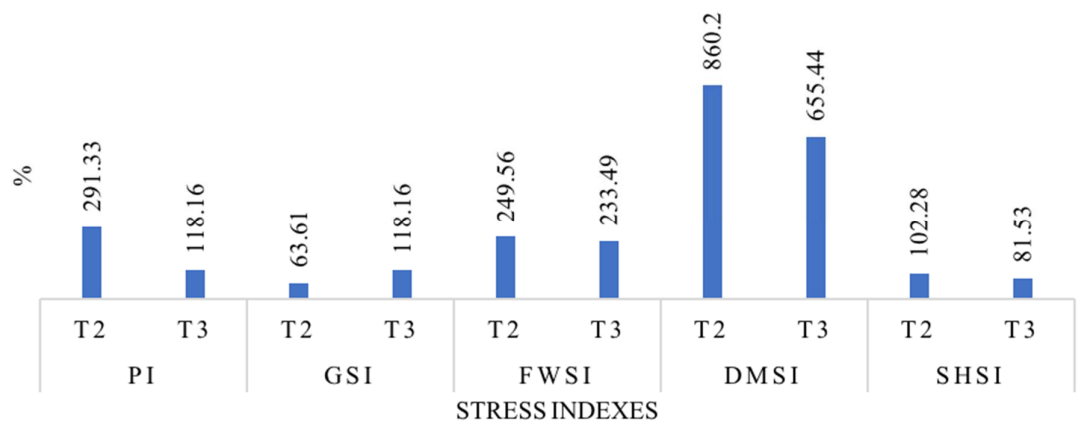

Figure 1. Mean comparisons of stress indexes of $\mathrm{T} 3$ with $\mathrm{T} 2$ in sunflower accessions

$\boldsymbol{P I}=$ Promptness index. $\boldsymbol{G S I}=$ Germination stress index. $\boldsymbol{F} \boldsymbol{W} \boldsymbol{S} \boldsymbol{I}=$ Fresh weight shoot index. $\boldsymbol{D} \boldsymbol{M S I}=$ Dry matter stress index. SHSI $=$ Seedling height stress index

Promptness index: It ranged from 29.03 to 904.35 and 52.99 to 216.35 of $\mathrm{T}_{2}$ and $\mathrm{T}_{3}$ respectively. The accession RHA-389 showed maximum promptness index $(904.35 \%$ and $216.35 \%)$ of both treatments $\left(\mathrm{T}_{2}\right.$ and $\mathrm{T}_{3}$ ) respectively, followed by HA-112 (727.96\%) only of $\mathrm{T}_{2}$ and 017573 (201.28\%) of $\mathrm{T}_{3}$. While minimum promptness index \% was observed in accession 017578 (29.03\%) followed by 017591 (68.56\%) of $\mathrm{T}_{2}$, and $\mathrm{T}_{3} 017591(52.99 \%)$ followed by $\mathrm{F}-\mathrm{Yu}-82$ (68.56\%).

Germination stress index: Range of germination stress index percentage of T2 was observed from 24.82 to 128.95 and unexpectedly an increase in GSI was observed in T3 i.e. 52.99 to 216.35 . The highest GSI was observed in RHA-389 (128.95\%, 216.35\%) of both treatments respectively followed by HA112 (123.02\%) of $\mathrm{T}_{2}$ and HA-341 (195.24\%) of $\mathrm{T}_{3}$. Minimum GSI was found in the accession 017591 (24.82\% and $52.99 \%)$ of both treatments followed by $017593(26.17 \%)$ at $\mathrm{T}_{2}$ and Omskijskorospelyj $(56.65 \%)$ at $\mathrm{T}_{3}$.
Fresh weight stress index: It ranged from 47.25 to 2879.987 and 20.75 to 3882.77 of both treatments $T_{2}$ and $\mathrm{T}_{3}$ respectively. The accession A-75 had highest fresh weight stress index (2879.98\%) followed by 017583 (1766.71\%) while minimum FSI was observed in accession 017572 (47.25\%) followed by CM-612 (59.26\%) at $\mathrm{T}_{2}$. While under $\mathrm{T}_{3}$ the accession HBRS-1 had maximum fresh weight stress index (3882.71\%) followed by A-75 (2184.34\%) while minimum FSI was found in PEMS-R-88 (20.75\%) followed by 017577 (44.21\%).

Dry matter stress index: Range of dry matter stress index \% was from 51.49 to 14733.33 at $\mathrm{T}_{2}$ and 0.69 to 9633.33 at $\mathrm{T}_{3}$. Highest DMSI percentage was observed in the accession A-79 $(14733.33,9633.33)$ under both $\mathrm{T}_{2}$ and $\mathrm{T}_{3}$ treatments respectively, followed by $017583(10701.89 \%, 7391.07)$ at both treatment $T_{2}$ and $\mathrm{T}_{3}$. Minimum DSI was found in 017571 (51.49\%) followed by CM-612 (50.86\%) at $\mathrm{T}_{2}$ while the accession PEMS-R had minimum DSI (0.69\%) followed by $017570(14.51 \%)$ at $\mathrm{T}_{3}$. 
Seedling height stress index: Seedling height stress index $\%$ range was decreased at $\mathrm{T}_{3}$ level as compared to $\mathrm{T}_{2}$. It was ranged 50.41 to $140.03 \%$ under $\mathrm{T}_{2}$ while in $\mathrm{T}_{3}$ it was 38.35 to $139.24 \%$. The accession 017585 had maximum SHSI (140.03\%) followed by HA-112 (126.17\%) while minimum was in CM-621 (50.41\%) followed by HA-133 (67.15\%) at $\mathrm{T}_{2}$. The accession odesskij 19 had maximum SHSI (139.24\%) followed by 017566 (132.14\%) while minimum was found in 017578 (38.35\%) followed by RHA-418 (31.16\%) at $\mathrm{T}_{3}$.

Mean values of these stress indexes are considered suitable for the selection of the accessions under drought stress condition Darvishzadeh et al. (2010) but there is need to use simple, easily measurable traits to improve the efficiency of selection, a major challenge in plant breeding programs.

Principal component analysis: Principal component analysis facilitates in selection of genotypes when there are many accessions to be selected and many traits to be involved. In present research, all the indexes had more than 1 eigen value and cumulatively $47.74 \%$ total variance suggesting the importance of studied variables. Biplot for the principal components (PCA $1\left(\mathrm{~T}_{2}\right)$ and PCA $2\left(\mathrm{~T}_{3}\right)$ are presented in Figure 2 and Figure 3 respectively. In the PCA 1 the accessions 017583, A-75, A-79, 017592, G-33 and 017566 were drought tolerant accessions as these are falling in Quadrate I where all the indexes had showed positive response towards drought tolerance. But in Quadrate II the accessions A-48, A-23, HA-112, 017587, RHA 389, HA 124, G-61, 017568, RHA-118, 017573, HAU, R-sin-82, R-C-HT-82 and HBRS-1 were drought tolerant. Accessions CM-621, 017577, HA-124, HA133, HA-342, HA-341, HA-236, 017581 and PEMSR- 88 were selected as most drought sensitive from Quadrate IV (Figure 2).

From the PCA 2 the accessions A-75, 017583, A-79, 017592, G-64, G-33, 017576, Odesskij19

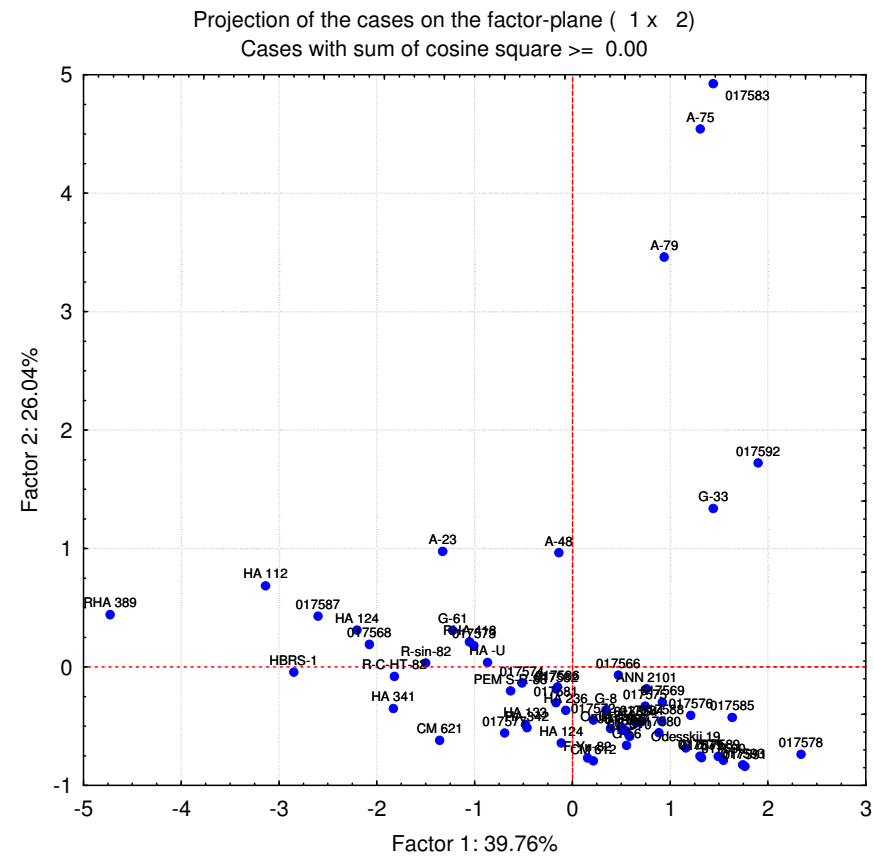

Figure 2. Principal component analysis of stress indexes of T2 in sunflower accessions 
and 017566 from Quadrate I were drought tolerant and the accessions HBRS-1, A-23, A-48 and G-61 Quadrate II. The accessions CM-621, 017577, HA-124, HA133, HA-342 and HA-341 were considered the most drought sensitive from Quadrate IV (Figure 3).
Overall in biplots (PCA 1 and PCA 2), the accessions 017583, A-75, A-79, 017592, G-33, 017566, A-48, A-23, G-61 and HBRS-1 were taken as drought tolerant and CM 621, 017577, HA-124, HA-133, HA-342 and HA-341 were as drought sensitive.

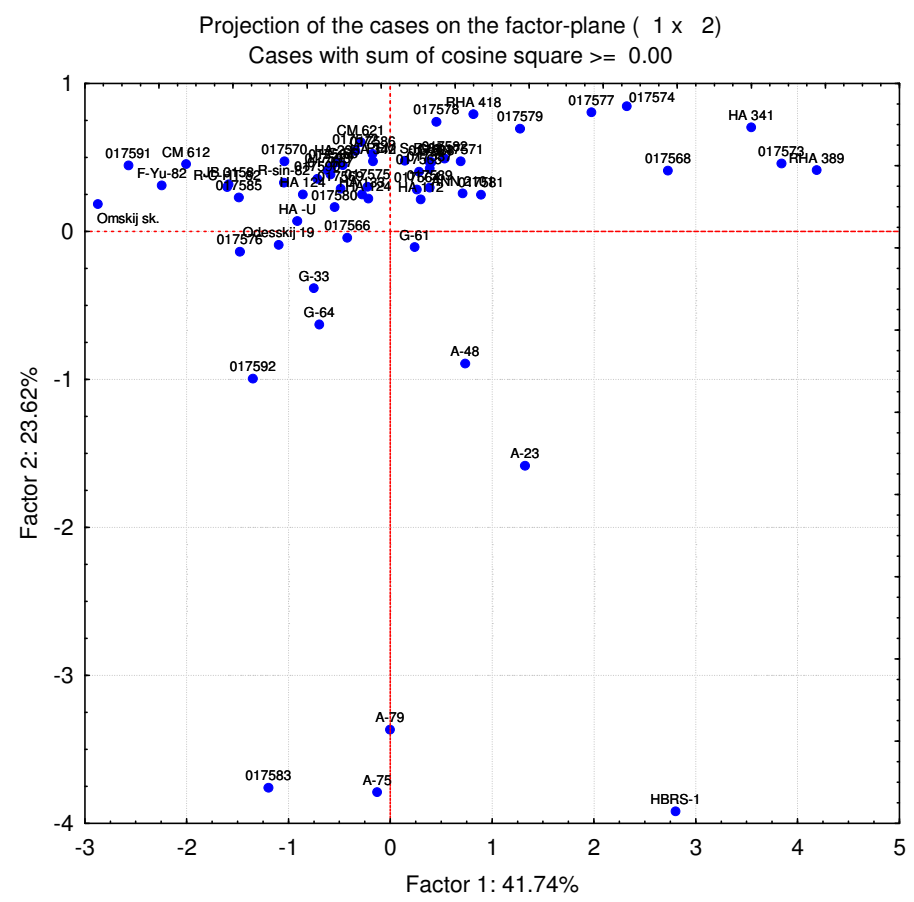

Figure 3. Principal component analysis of stress indexes of T3 in sunflower accessions

\section{Discussion}

The results of the experiment indicated that all the studied indexes decreased by increasing the level of drought stress except germination stress index. Decrease in indexes by increasing the drought stress has also been reported by various researchers Hsio (1973), Ahmad et al. (2009), Rauf and Sadaqat (2008), Rauf (2008), Hossain et al. (2010), Mehrpouyan et al. (2010), Ghaffari et al. (2012), Zlatev and Lidon (2012), Hussain et al. (2013) and Cavallaro et al. (2016). In the present study increase in germination stress index may be due to the different germplasm or effect of environment. However, many of the researchers did not consider the germination stress index as drought tolerance indicator but rather it may be used to indicate the seed quality and yield stability of accessions (Ashraf et al., 1996; Ahmad et al., 2009). Seed germination is affected by many factors such as seed age, size, 
maturity, storage conditions (Elemery, 1991), biochemical composition of seed (Reuzeanu et al., 1992), genetic differences (Sajjan et al., 1999) and environmental conditions (Smok et al., 1993). In present experiment, every effort was made to collect the seeds of same size, age and from same environmental conditions to diminish the effects of above mentioned factors on seed germination. Increase in germination stress index has also been reported in wheat Ashraf et al. (1996). The germination test may be useful for identifying vigorous seed lots and accessions capable of quickly establishing adequate population under low very low moisture conditions. But the genetic differences among diverse accessions may be correlated with seedling parameters which has also been studied in the present study.

Variation among the accessions for all the indexes except promptness index exhibited. Presence of genetic variability in the germplasm hence suggesting the effectiveness of selecting tolerant and sensitive accessions. Mean values of all the studied traits also showed the variability among the tolerant and sensitive accessions with high and low mean values respectively. Principal component biplot is considered a reliable and easy method for selecting tolerant and sensitive accessions Ghaffari et al. (2012). Among the 60 accessions the accessions 017583, A-75, A-79, 017592, G-33, A-48, A-23, G-61, HBRS-1 and 017566 were taken as drought tolerant, while the accessions CM-621, 017577, HA-124, HA-133, HA342 and HA-341 were observed as drought sensitive. These accessions may be used for the development of drought stress tolerant sunflower types. There are many reports which are in agreement with the present findings that drought stress severely reduce the growth and biomass of the plant. But the accessions having genetic potential to maintain the higher growth under stress conditions are drought tolerant.

\section{Conclusions}

Presence of the genetic variability among all the accession for all indexes except promptness index suggested that 017583, A-75, A-79, 017592, G-33, A-48, A-23, G-61, HBRS-1 and 017566 were drought tolerant and CM-621, 017577, HA-124, HA-133, HA-342 and HA341 These selected accessions may be used further study of drought stress and for the development of the drought stress tolerant types in sunflower. All the studied indexes except germination were found as more reliable drought stress indexes.

\section{References}

Ahmad, S., Ahmad, R. Ashraf, M.Y. Ashraf, M., Warraich, E.A. 2009. Sunflower (Helianthus annuus L.) response to drought stress at germination and seedling growth stages. Pakistan J. Bot. 42, 647-654.

Albuquerque, F.M.C., de Carvalho, N.M. 2003. Effect of type of environmental stress on the emergence of sunflower (Helianthus annuus L.), soybean (Glycine max (L.) Merril) and maize (Zea mays L.) seeds with different levels of vigor. Seed Sci. Technol. 31, 465-467.

Ashraf, M., Mehmood, S. 1990. Response of four Brassica species to drought stress. Environ. Expt. Bot. 30, 93-100.

Ashraf, M.Y., Akhtar, K. Hussain, F., Iqbal, J. 2006. Screening of different accessions of three potential grass species from Cholistan desert for salt tolerance. Pakistan J. Bot. 38, 1589-1597.

Ashraf, M.Y., Naqvi, M.H., Khan, A.H. 1996. Evaluation of four screening techniques for drought tolerance in wheat (Triticum aestivum L.). Acta Agron. Hung. 44, 213-220.

Cavallaro, V., Barbera, A.C., Maucieri, C., Gimma, G., Scalisi, C., Patane, C. 2016. Evaluation of 
variability to drought and saline stress through the germination of different ecotypes of carob (Ceratonia silique L.) using a hydrotime model. Ecological Engineering. 95, 557-566.

Darvishzadeh, R., Pirzad, A. Hatami-Maleki, H. Kiani, S.P., Sarrafi, A. 2010. Evaluation of the reaction of sunflower inbred accessions and their $\mathrm{F}_{1}$ hybrids to drought conditions using various stress tolerance indexes. Span. J. Agric. Res. 8, 1037-1046.

Dhanda, S.S. Sethi, G.S., Behl, R.K. 2004. Indexes of drought tolerance in wheat genotypes at early stages of plant growth. J. Agron. Crop Sci. 190, $1-6$.

Elemery, M.I. 1991. Effect of storage conditions (ToC and $\mathrm{RH} \%$ ) and packaging materials on germination percentage of onion and sunflower seeds. Ann. Agric. Sci. 29, 657-667.

Ghaffari, M. Toorchi, M. Valizadeh, M., Shakiba, M.R. 2012. Morpho-physiological screening of sunflower inbred accessions under drought stress condition. Turkish J. Field Crops 17, 185-190.

Gill, R.K., Sharma, A.D., Singh, P., Bhullar, S.S. 2002. Osmotic stress-induced changes in germination, growth and soluble sugar content of Sorghum bicolor (L.) Moench seeds. Bulg. J. Plant Physiol. $28,12-25$.

Hossain, M.I., Khatun, A. Talukder, M.S.A. Dewan, M.M.R., Uddin, M.S. 2010. Effect of drought on physiology and yield contributing characters of sunflower. Bangladesh J. Agric. Res. 35, 113-124.

Hsio, T.G. 1973. Plant responses to drought. Ann. Rev. Plant Physiol. 24, 519-570.

Hu, F.D., Jones, R.J. 2004. Effects of plant extracts of Bothriochloapertusa and Urochloamosambicensison seed germination and seedling growth of Stylosantheshamata cv. Veranoand Stylosanthesscabra cv. Seca. Aust. J. Agric. Res. 48, 1257-1264.
Hussain, S. Saleem, M.F. Ali, A. Iqbal, J., Shakir, M.A. 2013. Yield and quality improvement of sunflower (Helianthus annuus L.) hybrid through ABA application under water deficit conditions. J. Animal Plant Sci. 23, 1158-1165.

Kaya, M.D., Okcu, G., Atak, M., Cikili, Y., Kolsarici, O. 2006. Seed treatments to overcome salt and drought stress during germination in sunflower (Helianthus annuus L.). European J. Agron. 24, 291-295.

Ma, T., Wenzhi, Z., Qi, L., Jingwei, W. and Jiesheng, H. 2016. Effects of water, salt and nitrogen stress on sunflower (Helianthus annuus L.) at different growth stages. J. Soil Sci. Plant Nutrition. 16, 1024-1037.

Mehrpouyan, M., Gulshan, A.N., Sayfzadea, S. 2010. Effect of irrigation stop $t$ different growth stages on some agronomic traits of sunflower (Helianthus annuиs L.) under three plant densities in Takestan region, Iran. Plant Ecophysiol. 2, 137-144.

Mohammad, M. El, Benbella, M., Talouizete, A. 2002. Effect of sodium chloride on sunflower (Helianthus annuus L.) seed germination. Helia. 37, 51-58.

Murphy, D.J. 2010. Improvement of industrial oil crops, In: Industrial crops and used. CABI Int. Cambridge pp: 183-206. Singh, B. (ed).

Rauf, S. 2008. Breeding sunflower (Helinathus annuиs L.) for drought tolerance. Int. J. Faculty Agric. Biol. 3, 29-44.

Rauf, S., Sadaqat, H.A. 2008. Identification of physiological traits and genotypes combined to high achene yield in sunflower (Helinathus annuus L.) under contrasting water regimes. Australia J. Crop Sci. 1, 23-30.

Razzaq, H., Tahir, M.H.N. Sadaqat, H.A., Sadia, B. 2015. Genetic variability in sunflower accessions for achene yield and its related traits in sunflower. Int. J. Sci. Nature. 5, 669-676. 
Reuzeanu, C., Goffner, D., Cavalie, G. 1992. Relationship between protein composition and germination on capacity of sunflower seeds. Seed Sci. Res. 2, 223-230.

Sadeghian, S.Y., Yavari, N. 2004. Effect of waterdeficit stress on germination and early seedling growth in sugar beet. J. Agron. Crop Sci. 190, 138-144.

Sajjan, A.S., Badanur, V.P., Sajjanar, G.M. 1999. Effect of external water potential on seed germination, seedling growth and vigor index in some genotypes of sunflower. In: Proc. Symp. Recent Advances in Management of Arid Ecosystem (Eds.): S.A. Faroda, N.L. Joshi, S. Kathju and A. Kar. pp: 215-218.

Singh, B.D. 2000. Plant Breeding, Principals and Methods, New Delhi, India: Kalyani publishers pp: 896.

Smok, M.A., Chojnowski, M., Corbineau, F., Come, D. 1993. Effects of osmotic treatments on sunflower seed germination in relation with temperature and oxygen. In: Proc. 4th Intl. Workshop on seed: Basic and Applied Aspects of Seed Biology, (Eds.): D. Come and F. Corbineau. Angers, France pp: 1033-1038.
Tahir, M.H.N., Muhammad, I., Hussain, M.K. 2002. Evaluation of sunflower (Helianthus annuиs L.) inbred accessions for drought tolerance. Int. J. Agric. Biol. 3, 398-400.

Tian, F.P., Zhi, N.Z., Xiao, F.C., Lei, Sun, Xue, H.W., Gao, L.W. 2016. Effects of biotic and abiotic factors on soil organic carbon in semi-arid grassland. J. Soil Sci. Plant Nutrition. 16, 1087-1096.

Tsago, Y., Andargie, M., Takele, A. 2014. In vitro screening for drought tolerance in different sorghum (Sorghum bicolor L. Moench) varieties. J. Stress Physiol. Biochem. 9, 72-83.

Turhan, H. 1997. Salinity studies in potato (Solanum tuberosum L.). Ph.D. Thesis, The University of Reading UK. pp: 247.

Viscardi, S., Ventorino, V., Duran, P., Maggio, A., De Pascale, S., Mora, M.L., Pepe, O. 2016. Assessment of plant growth promoting activities and abiotic stress tolerance of Azotobacter chroococcum strains for a potential use in sustainable agriculture. J. Soil Sci. Plant Nutrition. 16, 848-863.

Zlatev, Z., Lidon, F.C. 2012. An overview on drought induced changes in plant growth, water relations and photosynthesis. Environ. J. Food Agric. 24, 57-72. 